\title{
Eye movement characteristics in male patients with deficit and non-deficit schizophrenia and their relationships with psychiatric symptoms and cognitive function
}

Lin Zhang ${ }^{1,2}$, Xiangrong Zhang ${ }^{1 *}$, Xinyu Fang ${ }^{1}$, Chao Zhou ${ }^{1}$, Lu Wen ${ }^{2}$, Xinming Pan ${ }^{2}$, Fuquan Zhang ${ }^{3}$ and Jiu Chen ${ }^{3}$

\begin{abstract}
Background: The cognitive impairment pattern of deficit schizophrenia (DS) is centered on an impaired attention function. Previous studies have suggested that the exploratory eye movement (EEM) tests reflect attention deficits in patients with schizophrenia. However, no study has investigated the characteristics of eye movement in DS in the Chinese Han population. This study aimed to investigate the pattern of eye movement characteristics in DS patients and to examine whether eye movement characteristic is associated with serious negative symptoms and cognitive decline in this schizophrenia subtype.
\end{abstract}

Methods: A total of 86 male patients [37 DS and 49 non-deficit schizophrenia (NDS)] and 80 healthy controls (HC) participated in this study. Clinical symptoms were assessed using the Scale for the Assessment of Positive Symptoms (SAPS) and Scale for the Assessment of Negative Symptoms (SANS). Cognitive function was assessed using the Mattis Dementia Rating Scale (MDRS-2). Eye movement data of subjects were collected using an eye movement tracking analyzer.

Results: There were significant differences in the overall eye movement data and cognitive test scores among the three groups (all $P<0.001$ ). Both DS and NDS schizophrenia subgroups showed more severe eye movement and cognitive impairment compared with the control group. The number of eye fixations (NEF), total of eye scanning length (TESL), and cognitive function in DS patients were significantly lower than those in NDS patients. The discriminant analysis (D score) was higher than that of the control group $(P<0.001)$. In the DS group, the inattention factor of SANS was negatively correlated with the attention factor $(r=-0.545, P=0.001)$ and structure factor of cognitive $(r=-0.389, P=0.023)$, the affective flattening factor of SANS was negatively correlated with TESL $(r=-0.353$, $P=0.041)$ and initiation/retention factor of cognitive $(r=-0.376, P=0.028)$. TESL was found to positively correlate with the MDRS-2 total score $(r=0.427, P=0.012)$, attention factor $(r=0.354, P=0.040)$, and memory factor $(r=0.349$,

*Correspondence: drxrz@hotmail.com

1 Department of Geriatric Psychiatry, The Affiliated Nanjing Brain Hospital

of Nanjing Medical University, No. 264 Guangzhou Road, Nanjing 210029,

Jiangsu, China

Full list of author information is available at the end of the article

(C) The Author(s) 2021. Open Access This article is licensed under a Creative Commons Attribution 4.0 International License, which permits use, sharing, adaptation, distribution and reproduction in any medium or format, as long as you give appropriate credit to the original author(s) and the source, provide a link to the Creative Commons licence, and indicate if changes were made. The images or other third party material in this article are included in the article's Creative Commons licence, unless indicated otherwise in a credit line to the material. If material is not included in the article's Creative Commons licence and your intended use is not permitted by statutory regulation or exceeds the permitted use, you will need to obtain permission directly from the copyright holder. To view a copy of this licence, visit http://creativecommons.org/licenses/by/4.0/. The Creative Commons Public Domain Dedication waiver (http://creativeco mmons.org/publicdomain/zero/1.0/) applies to the data made available in this article, unless otherwise stated in a credit line to the data. 
$P=0.043$ ) in the DS group, whereas the mean of eye scanning length (MESL) positively correlated with cognitive impairments in the NDS group. The negative symptoms showed no significant correlation with cognition in the NDS group.

Conclusions: Total of eye scanning length may be a characteristic eye movement symptom in DS patients, which is associated with serious negative symptoms and cognitive impairment in this schizophrenia subtype.

Keywords: Deficit schizophrenia, Exploratory eye movement, Mattis Dementia Rating Scale, Cognitive function

\section{Introduction}

Schizophrenia is a common and severe mental disease in clinical practice, which leads to social dysfunction [1], and might be the most disabling of all mental disorders [2]. Schizophrenia ranked 12th among 310 diseases and injuries worldwide in 2016 [3]. Charlson et al. reported the Global Burden of Disease (GDB) estimates for prevalence and disease burden of schizophrenia for all countries in 2016, and founded that about 21 million people worldwide suffer from schizophrenia, a number that will continue to rise as populations age and grow. Significant population growth and ageing have led to a large and increasing burden of disease caused by schizophrenia, particularly in middle-income countries [4]. The treatment of schizophrenia has made considerable progress, but about one-third of patients still have an unfavorable prognosis and continue to show decline in social functioning [5]. In 1988, Carpenter et al. proposed the concept of Deficit Schizophrenia (DS) subtype [6], characterized by primary and persistent negative symptoms; this classification is stable, with few changes in its core symptoms. However, the cognitive impairment pattern in DS is centered on the impaired attention function [7]. In addition, DS patients are characterized by familial aggregation, high birth rate in summer, poor long-term clinical efficacy, and early decline in social function [8, 9].

In 1972, Moriya et al. first reported eye movement abnormalities in schizophrenia patients using the exploratory eye movement (EEM) test [10]. Since then, most studies have consistently reported EEM disorders in schizophrenia patients [11-20]. EEM examination includes observation of the number of eye fixations (NEF), responsive of search scores (RSS), total of eye scanning length (TESL), the mean of eye scanning length (MESL), and the discriminant analysis (D score) [13, 21, 22]. NEF and RSS have been reported to reflect some characteristics of the cognitive function, including cognition, memory, attention, and other mental states of individuals $[11,23]$. EEM examination has been regarded as a biological indicator of schizophrenia [14], which can reflect visual cognitive dysfunction and attention deficit in patients with schizophrenia [24, 25]. Previous studies have shown that most patients with schizophrenia have abnormal eye trajectories [14], a smaller number of fixations on memory tasks, and a narrower range of eye movements compared with healthy controls [11, 19, 26-28]. Existing research has shown that TESL and RSS in patients with schizophrenia are negatively correlated with negative symptoms such as emotional withdrawal and flatness [14].

Ample studies have further reported that patients with DS have more severe impairment in almost all cognitive domains [29]. Especially executive function [30, 31] and speech fluency [32-36] compared with patients with non-DS (NDS). Réthelyi et al. found that neurocognitive performance in general and in all cognitive domains except short-term memory were significantly reduced in patients with schizophrenia with deficits. Patients with DS and NDS had greater problems with non-verbal flexibility (TMT) than with linguistic cognitive flexibility (VFT P) [36]. Tyburski et al. found that the concept formation level of DS patients was lower than that of NDS patients, and the non-verbal cognitive flexibility level of DS patients was lower than that of NDS patients [37]. Negative symptoms are a core component of DS [6], and are associated with a large proportion of long-term morbidity and poor functional outcome cases in DS patients.

At present, the etiology of schizophrenia is complex, involving multi-gene inheritance, the pathogenesis has not been clear, the diagnosis is based on clinical professional psychiatrists, through the understanding of the patient's history and mental examination, referring to clinical diagnostic criteria for diagnosis, lack of specific objective diagnostic indicators. In previous studies, the eye movement pattern of patients with schizophrenia was significantly different from that of normal or nonschizophrenic patients, and the sensitivity and specificity of EEM were greater than $70 \%$ and $80 \%$ in distinguishing schizophrenic patients from non-schizophrenic patients, respectively [8, 21, 38, 39]. In 2009, Suzuki and his team performed a series of deterministic analyses of SZ and non-SZ subjects using the EEM examination study alone, Of 251 patients with clinically diagnosed SZ, 184 were determined to be true positive (sensitivity 73.3\%) [21]. These results suggest that EEM may contribute to the clinical diagnosis of schizophrenia. However, it is unclear whether there is a difference in eye movement data between patients with DS and patients with NDS. 
Therefore, the purpose of the study was to compare exploratory eye movements of healthy controls with those of DS patients, NDS patients, the participants were also assessed by the Revised Mattis Dementia Rating Scale (MDRS-2) for measuring cognitive functions [40], such as sustained attention and memory function. To determine if there are any differences in eye movement and cognition between DS and NDS patients. The second aim is to assess which stimulus factors or parts of the stimulus factors are responsible for the significant differences. We hypothesized that patients with DS and NDS have different cognitive patterns and eye movement characteristics, and that eye movement and cognitive function have their own correlation characteristics in the two subtypes of schizophrenia.

\section{Methods}

\section{Participants}

In all, 166 male participants were recruited in this study, including 86 schizophrenia patients who were clinically stable (37 DS and 49 NDS) and 80 health control (HCs). The schizophrenia patients were recruited from the Department of Psychiatry at the Second People's Hospital of Jiangning District in Nanjing, Jiangsu Province, China. The following individuals were included in the analysis: (1) individuals diagnosed with schizophrenia according to Diagnostic and Statistical Manual of Mental Disorders, Fourth Edition (DSM-IV), confirmed by the Chinese version of the Structured Clinical Interview for DSM-IV (SCID-I) [41]; (2) male, right-handed, Chinese Han patients aged between 25 and 65 years; and (3) individuals showing stable psychiatric symptoms and taking antipsychotic medication for at least 12 months based on the medical record. The exclusion criteria included the following: neurological disorders, severe comorbid conditions, head trauma, mental retardation, alcoholism or substance abuse disorder, and a history of previous electroconvulsive therapy. All DS and NDS patients were diagnosed according to the Chinese version of the Schedule for the Deficit Syndrome (SDS) [42].

The 80 male HCs were recruited from the local community and matched for age and handedness of the enrolled patients. The inclusion criteria: (1) male, righthanded, Chinese Han patients aged between 25 and 65 years; (2) Years of education $\geq 6$ years. (3) These healthy subjects were assessed using unstructured clinical interviews to obtain basic demographic information as well as psychosocial information (age, education, living and marital status, family background, etc.) to rule out individuals with organic brain disorders, mental retardation or severe head trauma, and a personal or family history of mental disorders. The exclusion criteria: None of them had any drug or alcohol abuse/dependence, nor did they have severe visual impairment or red-green color blindness. They had no history of mental disorders personally or in their families. The study was approved by the Institutional Ethical Committee for clinical research of the Second People's Hospital of Jiangning District in Nanjing, and written informed consent was obtained from all participants.

\section{Clinical and neuropsychological assessment Clinical evaluation}

After consistency training, a semi-structured interview that achieved a high inter-rater reliability [intraclass correlation coefficient $(\mathrm{ICC})=0.84$ ] was conducted by two senior attending physicians. The deficit syndrome was determined according to the Chinese version of SDS [43]. The diagnostic criteria for SDS include the presence of two or more of the following negative symptoms: a deficit syndrome that has reached clinical significance, has persisted for more than 12 months, and has persisted during periods of clinical stability. These symptoms were primary or idiopathic and not secondary to depression, anxiety, drug side effects, psychotic symptoms, or mental retardation. Our diagnostic criteria were in line with the DSM-IV diagnosis of schizophrenia. The Scale for the Assessment of Positive Symptoms (SAPS) and the Scale for the Assessment of Negative Symptoms (SANS) was used to evaluate the positive and negative symptoms of patients, respectively, for assessing the severity of schizophrenia symptoms. SANS scale was classified into separate categories including diminished expression, social amotivation, and inattention factors based on the findings of the most comprehensive factor analysis of the 19-item SANS to date [44].

\section{Neurocognitive assessments}

Each participant was assessed using MDRS-2, based on previous reports on cognitive process assessment for each task. These cognitive measures were further divided into five areas of reasonable motivation: continuous vigilance/attention (hereinafter referred to as continuous attention), initiation/retention, concept formation, structure, and memory [40].

\section{Exploratory Eye Movement (EEM) recording}

The EEM examination was performed in 86 patients with schizophrenia and 80 HCs using DEM-2000 eye movement detection system (Shanghai Dikang, China). The EEM test procedure was based on that reported by Kojima et al. [12]. A standard 9-point calibration was performed before task initiation. A monocular sampling method was used to track the pupil of the dominant eye. EEM images were recorded on a videotape with an eyemark recorder based on the reflection of infrared light on 
the cornea. The numbers of eye fixations (NEF), responsive of search scores (RSS), total eye scanning length (TESL), and mean eye scanning length (MESL) of the patient during the first $15 \mathrm{~s}$ of viewing a target figure was analyzed [14, 21, 22].

\section{Eye movement recording procedure}

First, the subject was comfortably seated in the viewing room, an eye camera that detected corneal reflection of infrared light to identify eye movements, and an LCD monitor that displayed target figures for EEM tasks were included in this system. Then, three horizontal S-shaped figures were projected onto a screen positioned at $30 \mathrm{~cm}$ directly in front of the subject's eyes. The first S-shaped figure (S1) was displayed on the screen for $15 \mathrm{~s}$. The second and third S-shaped figures (S2, S3), which were slightly different from the first one, were then displayed on the screen, each figure lasting for $15 \mathrm{~s}$. Following this, the subject was asked whether the last two figures differed from the first figure and, if they did, how did they differ.

The gaze point (NEF) is the total number of points in the eye fixation pattern $\mathrm{S} 1$ within $15 \mathrm{~s}$, and the duration of a certain point in the eye fixation image should be more than $200 \mathrm{~ms}$. The RSS score is calculated by dividing S2 or S3 into 7 areas. The instrument measures the number of areas that the eyes focus on, for a total of $5 \mathrm{~s}$. As long as the subjects' eyes gaze at a certain area, one point is counted, regardless of how many times this area is looked at. Therefore, the maximum RSS score for each image is 7 points, and the total RSS score for S2 and S3 is 14 points. The $\mathrm{D}$ score is calculated according to the discriminant analysis formula, $\mathrm{D}=10.265-[(0.065 \times \mathrm{N}$ $\mathrm{EF})+(0.871 \times \mathrm{RSS})]$. The extent of the eye fixation point is TESL. MESL is the mean extent of eye movement. In the digital eye-mark recording system, the detected eye movements were automatically analyzed by a digital computerized EEM analyzer [14, 21].

\section{Statistical analysis}

All statistical analyses were performed using the SPSS 26.0 software. We have used Kolmogorov-Smirnov statistical method to check the normal distribution of variables. The continuous variables of demographics, clinical symptoms, eye movement, and cognitive function between groups are presented as mean \pm SD or Median (quartile spacing), and using two sample t-tests, analysis of variance (ANOVA) or Non-parametric test for comparisons, as appropriate. The qualitative data were analyzed by Chi-square test. EEMs, cognitive function, and psychiatric symptoms were compared using two sample $t$-tests between DS and NDS groups. Age and years of education were used as covariables to conduct covariance analysis on the data of the two groups. $P<0.05$ was considered statistically significant.

We have used Kolmogorov-Smirnov statistical method to check the normal distribution of variables. To determine the group differences in eye movement and cognition function, statistical comparisons were performed on eye movement indices (such as NEF, RSS, D score, TESL, and MESL) and cognitive function indices (such as continuous vigilance/attention, initiation/retention, concept formation, structure, and memory) among the three groups Non-parametric tests. Partial correlation analysis between eye movements and neurocognitive domain and clinical variables (with age, years of education, and duration of disease as covariate) was conducted in the two patient groups. The significance level was set at $P<0.05$. Bonferroni at $P<0.05$ was applied to correct for multiple comparisons. After comparing the differences in various indicators between the two subgroups, the variables with differences $(P<0.05)$ between the two subgroups were finally included (the duration of disease, NEF, TESL, concept formation, structure and memory) in the stepwise logistical regression analysis to explore the independent risk factor for DS. The G*Power 3.1.9.2 program (http:// www.softpedia.com/get/Science-CAD/G-Power.shtml) was used to run a power calculation and determine the effect size [45].

\section{Results}

Demographic and clinical characteristics

Demographic and clinical characteristics of the subjects are presented in (Table 1). The analysis of variance (ANOVA) results showed significant differences in age $(F=9.819, P<0.001)$ and education $(F=28.024$, $P<0.001)$ among the three groups. Bonferroni's posthoc comparisons revealed shorter education periods in the DS $(P<0.001)$ and NDS $(P<0.001)$ groups relative to those in the $\mathrm{HC}$ group, although the two patient subgroups did not differ significantly $(P=0.969)$. The DS $(P=0.001)$ and NDS $(P=0.009)$ patients were older than the HC subjects, but there was no significant difference between the two patient subgroups $(P=0.093)$. Our results indicated that significant differences in family history $(P<0.001)$ and marital status $(P<0.001)$ among the three groups, but the two patient subgroups had no significant differences in terms of family history $(P=0.209)$, marital status $(P=0.754)$, the mean age at onset, smoking status, positive symptoms, and antipsychotic medicine dosage (chlorpromazine equivalents), except for duration of disease $(t=3.771, P<0.001)$ in the DS group. The DS patients showed more severe negative symptoms $(P<0.001)$ than the NDS patients. 
Table 1 Demographics and clinical characteristics for DS, NDS and HC groups

\begin{tabular}{|c|c|c|c|c|c|}
\hline & $\mathrm{DS}(\mathrm{n}=37)$ & NDS $(n=49)$ & $\mathrm{HC}(\mathrm{n}=80)$ & $F / Z / X^{2} / t$ & $P$ \\
\hline Age (years) & $50.00 \pm 10.509 \triangle$ & $45.86 \pm 10.809^{\#}$ & $40.48 \pm 11.842$ & 9.819 & $<0.001$ \\
\hline Education (years) & $9.65 \pm 2.251^{\triangle}$ & $10.35 \pm 3.244^{\#}$ & $13.78 \pm 3.590$ & 28.024 & $<0.001$ \\
\hline Age at onset (years) & $23.7365 \pm 6.76$ & $26.61 \pm 9.808$ & & -1.612 & 0.111 \\
\hline Duration of disease (years) & $26.27 \pm 9.137^{* *}$ & $19.04 \pm 8.541$ & & 3.771 & $<0.001$ \\
\hline CPZ-equivalent daily dose (mg/day) & $375(280)$ & $360(210)$ & & -0.725 & 0.468 \\
\hline Marital status [example (\%) & & & & 60.169 & $<0.001$ \\
\hline Unmarried & $30(33.7)$ & $41(46.1)$ & $18(20.2)$ & & \\
\hline Married & $7(9.1)$ & $8(10.4)$ & $62(80.5)$ & & \\
\hline Family history [example (\%)] & & & & 40.653 & $<0.001$ \\
\hline Positive & $17(51.5)$ & $16(48.5)$ & $0(0.0)$ & & \\
\hline Negative & $20(15.0)$ & $33(24.8)$ & $80(60.2)$ & & \\
\hline Use rate of anticholinergic drugs [example (\%) & $17(54.8)$ & $14(45.2)$ & & 2.761 & 0.097 \\
\hline Smoking ratio (\%) & $13(18.6)$ & $26(37.1)$ & $31(44.3)$ & 3.518 & 0.172 \\
\hline SDS total score & $13.62 \pm 1.846^{* *}$ & $8.86 \pm 2.111$ & & 10.927 & $<0.001$ \\
\hline SAPS total score & $9.22 \pm 2.083$ & $9.67 \pm 0.944$ & & -1.364 & 0.176 \\
\hline Hallucinations & $1.57 \pm 0.603$ & $1.57 \pm 0.500$ & & -0.259 & 0.796 \\
\hline Delusions & $2.08 \pm 0.894$ & $2.29 \pm 0.540$ & & -1.317 & 0.191 \\
\hline Bizarre behavior & $3.05 \pm 0.911$ & $2.98 \pm 0.989$ & & 0.357 & 0.722 \\
\hline Positive thought disorder & $2.54 \pm 0.869$ & $2.84 \pm 0.624$ & & -1.840 & 0.069 \\
\hline SANS total score & $44.81 \pm 5.929^{* *}$ & $31.27 \pm 4.729$ & & 11.786 & $<0.001$ \\
\hline Affective flattening & $11.30 \pm 1.525^{* *}$ & $9.12 \pm 1.889$ & & 5.904 & $<0.001$ \\
\hline Alogia & $10.76 \pm 2.006^{* *}$ & $6.90 \pm 1.403$ & & 10.000 & $<0.001$ \\
\hline Avolition & $8.65 \pm 1.495^{* *}$ & $5.53 \pm 1.101$ & & 10.687 & $<0.001$ \\
\hline Anhedonia & $9.81 \pm 2.526^{* *}$ & $6.24 \pm 1.164$ & & 7.972 & $<0.001$ \\
\hline Inattention & $4.41 \pm 0.927^{* *}$ & $3.47 \pm 0.68$ & & 5.180 & $<0.001$ \\
\hline
\end{tabular}

Mean \pm SD; Median (quartile spacing); DS: defificit schizophrenia; NDS: non-defificit schizophrenia; HC: healthy controls; SANS: the Scale for the Assessment of Negative Symptoms; SAPS: the Scale for the Assessment of Positive Symptoms; SDS: schedule for the defificit syndrome; CPZ: chlorpromazine

${ }^{* *} P<0.001$ DS vs. NDS;

${ }^{*} P<0.05$ DS vs. NDS;

$\triangle P<0.05$ DS vs. HC;

${ }^{\#} P<0.05$ NDS vs. HC

\section{Cognitive characteristics}

The results of normality test showed that MDRS-2 score and subscale score among the three groups were all almost non-normal $(\mathrm{P}<0.05)$. Then, we have conducted a Kruskal-Wallis non-parametric test. Our results showed significant differences among the three groups (all $P<0.001$ ). Bonferroni's post-hoc comparisons confirmed that both the DS and NDS patients performed worse than the $\mathrm{HC}$ subjects in each of the neuropsychological tests (all $P<0.001$ ). Patients with DS, as compared with those with NDS, had significantly more severe impairment in most of the neuropsychological measures (Bonferroni corrected $P<0.05$ ) (Table 2). As the family history and marital status varied among the $\mathrm{HC}$ subjects, DS and NDS patients, we further made a stratification by the family history and marital status to compare the cognitive function among these three groups, the results showed in the Additional file 1: Table S1 and Table S2.

\section{Characteristics of eye movement parameters}

Figures 1, 2, and 3 show a typical example of an eye scanning trajectory of a DS patient, an NDS patient, and a healthy control. The frequency of eye fixation points (NEF) were lowest and the total eye scanning length (TESL) were the shortest in DS patients. Nonparametric test analysis showed that there were statistically significant differences in eye movement indices among the three groups (all $P<0.001$ ). As the family history and marital status varied among the $\mathrm{HC}$ subjects, DS and NDS patients, we further made a stratification by the family history and marital status to compare the eye movement parameters among these three groups, the results showed in the Additional file 1: Table S1 and Table S2. Bonferroni's post-hoc comparisons showed that patients with DS $(P<0.001)$ and NDS $(P<0.001)$ had worse eye movement parameters than $\mathrm{HC}$ subjects. NEF and TESL in the DS group were significantly lower than 
Table 2 Eye movement and cognitive function for DS, NDS and HC groups

\begin{tabular}{|c|c|c|c|c|c|c|c|c|c|c|c|}
\hline & \multirow[t]{2}{*}{$\mathrm{DS}(n=37)$} & \multirow[t]{2}{*}{$\operatorname{NDS}(n=49)$} & \multirow[t]{2}{*}{$\mathrm{HC}(\mathrm{n}=80)$} & \multirow[t]{2}{*}{$\mathrm{H}$} & \multirow[t]{2}{*}{$P$} & \multicolumn{2}{|c|}{ DS VS NDS } & \multicolumn{2}{|l|}{ DS VS HC } & \multicolumn{2}{|c|}{ NDS VS HC } \\
\hline & & & & & & $\mathbf{H}$ & $\mathbf{P}$ & H & $\mathbf{P}$ & $\mathrm{H}$ & $\mathbf{P}$ \\
\hline NEF(score) & $22(14)$ & $27(11)$ & $30(4)$ & 44.41 & $<0.001$ & -2.480 & 0.013 & -6.381 & $<0.001$ & -4.015 & $<0.001$ \\
\hline RSS (score) & $3(2)$ & $4(2)$ & $7(1)$ & 96.59 & $<0.001$ & -1.246 & 0.213 & -8.394 & $<0.001$ & -7.704 & $<0.001$ \\
\hline D score & $5.9(2.3)$ & $4.9(2.8)$ & $2(1.3)$ & 98.26 & $<0.001$ & 1.424 & 0.154 & 8.553 & $<0.001$ & 7.664 & $<0.001$ \\
\hline TESL & $120.2(123)$ & $192.6(155)$ & $281.8(112)$ & 60.06 & $<0.001$ & -2.706 & 0.007 & -7.636 & $<0.001$ & -4.820 & $<0.001$ \\
\hline MESL & $6.3(4.9)$ & $8.9(4.8)$ & $11(5.6)$ & 40.06 & $<0.001$ & -1.156 & 0.248 & -5.583 & $<0.001$ & -4.731 & $<0.001$ \\
\hline MDRS-2 score & $82(34.5)$ & $112(26)$ & $139(6)$ & 124.92 & $<0.001$ & -2.577 & 0.010 & -10.105 & $<0.001$ & -7.981 & $<0.001$ \\
\hline Continuous vigilance/ attention & $34(5.5)$ & $36(2)$ & $37(0)$ & 80.50 & $<0.001$ & -1.888 & 0.059 & -8.031 & $<0.001$ & -6.535 & $<0.001$ \\
\hline Initiation/ retention & $13(11)$ & $23(13)$ & $36(2)$ & 121.25 & $<0.001$ & -2.316 & 0.021 & -9.856 & $<0.001$ & -8.022 & $<0.001$ \\
\hline Concept formation & $17(18)$ & $28(9.5)$ & $35(3)$ & 108.45 & $<0.001$ & -2.606 & 0.009 & -9.504 & $<0.001$ & -7.287 & $<0.001$ \\
\hline Structure & $5(3.5)$ & $6(1)$ & $6(0)$ & 49.01 & $<0.001$ & -2.913 & 0.004 & -6.792 & $<0.001$ & -3.946 & $<0.001$ \\
\hline Memory & $14(9.5)$ & $20(5.5)$ & $25(0)$ & 125.08 & $<0.001$ & -3.044 & 0.002 & -10.308 & $<0.001$ & -7.642 & $<0.001$ \\
\hline
\end{tabular}

Median (quartile spacing); $\mathrm{H}$ : The effect size of nonparametric tests; P: significance level; NEF: the numbers of eye fixations; RSS: responsive of search scores; TESL: total eye scanning length; MESL: mean eye scanning length; MDRS: Dementia Rating Scale

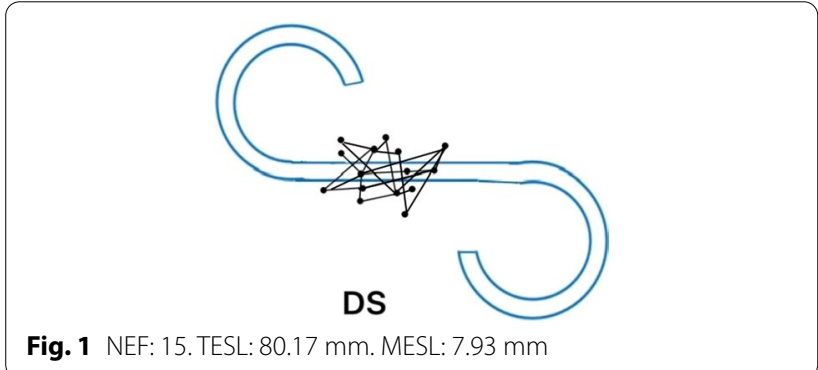

Fig. 1 NEF: 15. TESL: $80.17 \mathrm{~mm}$. MESL: $7.93 \mathrm{~mm}$

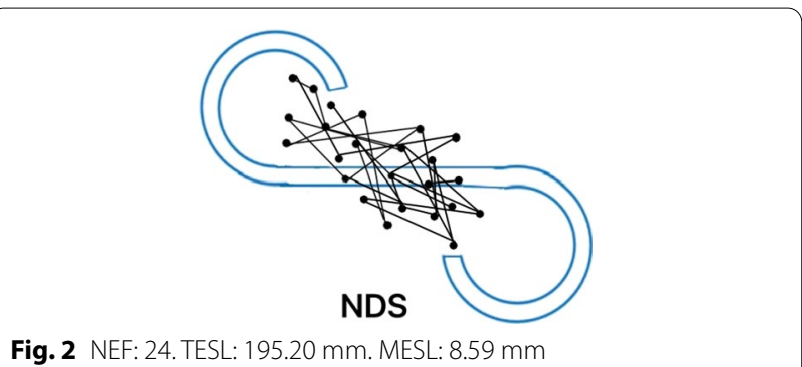

Fig. 2 NEF: 24. TESL: 195.20 mm. MESL: 8.59 mm

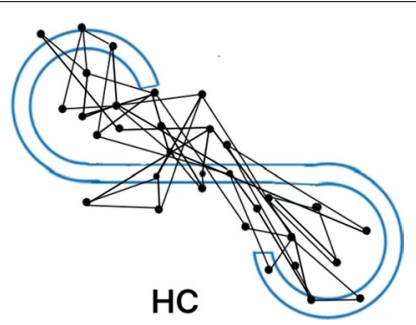

Fig. 3 NEF: 32. TESL: $283.40 \mathrm{~mm}$. MESL: $12.06 \mathrm{~mm}$ those in the NDS group (Bonferroni corrected $P<0.05$ ). There were no statistically significant differences in RSS, MESL and D value between the two groups (both $P>0.05$ ) (Table 2, Figs. 1, 2, 3). The statistical power of our study to detect the difference of NEF, RSS, D score, TESL, MESL, MDRS-2 score, continuous vigilance/attention, initiation/retention, concept formation, structure, memory between patients and healthy controls were all $100 \%$.

\section{Relationships between eye movement, clinical features, and cognitive domains}

With age, years of education, and duration of disease as covariables, the clinical symptoms, eye movement indices, and cognitive indices in the DS and NDS groups were analyzed by partial correlation. The bizarre behavior factor of SAPS in the DS group was negatively correlated with NEF $(\mathrm{r}=-0.545, P=0.001)$ and memory factor $(\mathrm{r}=-0.347, P=0.045)$ and positively correlated with $\mathrm{D}$ value $(\mathrm{r}=0.396, P=0.020)$. The affective flattening factor of SANS was negatively correlated with TESL $(\mathrm{r}=-0.353, P=0.041)$ and initiation/retention factor of cognitive $(\mathrm{r}=-0.376, P=0.028)$. The inattention factor of SANS was negatively correlated with the MDRS-2 total score $(\mathrm{r}=-0.468, P=0.005)$, attention factor $(\mathrm{r}=-0.545, P=0.001)$, and structure factor $(\mathrm{r}=-0.389$, $P=0.023)$. TESL was positively correlated with MDRS-2 score $(\mathrm{r}=0.427, P=0.012)$, attention factor $(\mathrm{r}=0.354$, $P=0.040)$, and memory factor $(\mathrm{r}=0.349, P=0.043)$.

MESL was positively correlated with the inattention factor of SANS( $r=0.337, P=0.022)$, MDRS-2 total score $(\mathrm{r}=0.401, P=0.006)$, initiation/retention factor $(\mathrm{r}=0.349, P=0.018)$, and concept formation factor $(\mathrm{r}=0.392, P=0.007)$ in the NDS group. The negative 
Table 3 Correlation of eye movement with cognitive and clinical symptoms in DS group

\begin{tabular}{lllllcccc}
\hline & NEF & TESL & MDRS-2 total score & $\begin{array}{l}\text { Continuous } \\
\text { vigilance/ } \\
\text { attention }\end{array}$ & Initiation/retention & Structure & Memory \\
\hline SAPS & Bizarre behavior & $-0.545^{* *}$ & -0.226 & -0.210 & -0.009 & -0.137 & -0.019 & $-0.347^{*}$ \\
SANS & Affective flattening & -0.178 & $-0.353^{*}$ & -0.145 & 0.014 & $-0.376^{*}$ & -0.206 \\
& Inattention & -0.120 & -0.323 & $-0.468^{* *}$ & $-0.545^{* * *}$ & -0.270 & $-0.389^{*}$ & -0.263 \\
& TESL & $0.518^{* *}$ & - & $0.427^{*}$ & $0.354^{*}$ & 0.293 & 0.214 & $0.349^{*}$ \\
\hline
\end{tabular}

${ }^{*} P<0.05$ after correction of multiple testing

${ }^{* *} P<0.01$ after correction of multiple testing

***P $P<0.001$ after correction of multiple testing

Table 4 Correlation of eye movement with cognitive and clinical symptoms in NDS group

\begin{tabular}{|c|c|c|c|c|c|c|c|}
\hline & & NEF & MESL & TESL & $\begin{array}{l}\text { MDRS - } 2 \text { total } \\
\text { score }\end{array}$ & $\begin{array}{l}\text { Initiation/ } \\
\text { retention }\end{array}$ & Concept formation \\
\hline SAPS & Bizarre behavior & 0.068 & -0.263 & -0.229 & 0.203 & 0.038 & 0.238 \\
\hline \multirow[t]{2}{*}{ SANS } & Inattention & -0.122 & $0.337^{*}$ & $0.308^{*}$ & 0.121 & 0.017 & 0.222 \\
\hline & MESL & -0.252 & - & $0.649^{* *}$ & $0.401^{* *}$ & $0.349^{*}$ & $0.392^{* *}$ \\
\hline
\end{tabular}

${ }^{*} P<0.05$ after correction of multiple testing

${ }^{*} P<0.01$ after correction of multiple testing

symptoms showed no significant correlation with cognition in the NDS group (Table 3, 4). Stepwise logistic regression analysis showed that duration of disease (odds ratio [OR] 1.081, 95\% confidence interval [CI] 1.0161.150, $\mathrm{P}<0.05$ ), memory (odds ratio [OR] $0.803,95 \% \mathrm{CI}$ $0.718-0.897, \mathrm{P}<0.001$ ), and TESL (odds ratio [OR] 0.992, $95 \%$ CI $0.986-0.998, \mathrm{P}<0.05)$ were independently associated with DS.

\section{Discussion}

To the best of our knowledge, this is the first study to investigate eye movement characteristics in patients with DS and their correlation with clinical symptoms and cognition. The main findings of our study were as follows: in the DS group and NDS group, eye movement index and cognitive function were generally low, and the impairment of eye movement index in DS group (i.e., lower NEF and TESL) was greater than that in the NDS group. DS patients showed greater impairments in all cognitive function measures than NDS patients [29]. Both schizophrenia subgroups performed worse than the control group in every area of eye movement measurement and cognition. In addition, NEF was significantly correlated with SAPS bizarre behavior factor in the DS group, whereas TESL was correlated with SANS affective flattening factor, cognitive MDRS total score, attention factor, and memory factor in the DS group. Further study found that TESL in DS group was related to emotional state of SANS, memory function of cognitive and disease duration. TESL and memory function of DS patients significantly affected the patient's condition. However, MESL was associated with inattention of SANS, executive function, and visuospatial ability of cognitive in the NDS group. The two patient groups had different patterns of core eye movement damage, which suggested that DS might be an independent subtype of schizophrenia, and TESL might be a biomarker for the diagnosis of DS.

NEF and RSS reflect cognitive function such as memory and active attention, whereas TESL is associated with emotional withdrawal, and blunted effect and emotional relationship disorder [27]. The previous studies have found the lower the NEF, the shorter the TESL and the narrower the range of eye movement in the patients with schizophrenia, suggesting that limited scanning length may be a characteristic of schizophrenia $[14,19,28]$. Less eye movement was believed to be a sign of impaired visual cognitive function [12, 14, 15, 22]. A significant reduction in the scan length may be because of lack of sustained attention [27]. In this study, both DS and NDS patients presented with lower NEF and shorter TESL, which was largely compatible with several previous studies, indicating decreased eye movement in schizophrenia $[14,19,28]$. In addition, in our study, the differences of NEF and TESL between DS patients and NDS patients in Figs. 1 and 2 were significant, and the MESL of DS did not change significantly, indicating that they were 
state independent. Kojima et al. [14] reported in 1990 that TESL depended on clinical status and was a status marker. These studies also suggest that MESL abnormalities are specific to patients with chronic schizophrenia and are an indicator of a chronic state. Ryu et al. observed that individuals with schizophrenia may stare aimlessly at a certain part of the picture rather than properly focusing their attention on that part of the picture [27]. Shakow reported that people with schizophrenia were unable to focus their attention on the external environment or move in a meaningful direction [46]. In terms of face recognition, Williams et al. reported that under more difficult task conditions, schizophrenia patients could not focus their eye gaze on characteristic areas; they thought that these patients could not form the general gestalt of the initial registration, followed by abnormal stress of serial processing. These studies found that patients with schizophrenia in a variety of eye movement task execution process of aberrations [47]. Restricted facial visual scanning may indicate social cognitive impairment or may be a marker of vulnerability associated with disease features $[48,49]$. These findings indicate that abnormal eye movement may be a common feature in schizophrenia, regardless DS and NDS, but the decrease was more pronounced in DS patients. These gaze points in DS patients were few and also relatively fixed and limited. The eyes of DS patients tend to be fixated at a single point or move within a particularly limited range, which significantly shortens the total eyeball distance. This may be closely related to the disease characteristics of DS patients. In our study, it was found that DS patients were more indifferent to the surrounding environment, passive contact, more passive in eye movement examination and scale evaluation, less speech, stiff expression after hearing questions, less eye movement and shorter TESL. Persistent negative symptoms caused the patient to be unable to concentrate on a particular instruction. DS patients with emotional withdrawal, anhedonia, resulting in patients in interpersonal communication and social interaction on the obstacles.

Schizophrenia patients have cognitive impairments in attention, working memory, language learning, visual learning, social cognition, and other aspects [50, 51]. Previous studies have reported that EEM abnormalities in schizophrenia are associated with cognitive impairment [52-55]. Several studies have shown differences in neurocognitive function between patients with DS and NDS $[56,57]$. Previous studies have found that DS patients had more severe impairment in almost all cognitive domains when compared with NDS patients [29]. A meta-analysis by Cohen et al. reported evidence of moderate widespread cognitive impairment in patients with defect syndrome [58]. Previous studies have found that schizophrenia patients with persistent negative symptoms showed more severe continuous attention impairment in related cognitive assessments [59-61]. A modified version of MDRS was used in this study [40, $62,63]$. The present study found that both schizophrenia subgroups performed worse compared with the control group in every cognitive area. These reflected the overall impairment of cognitive function in schizophrenia. Compared with NDS patients, DS patients had more severe impairments in all neurocognitive domains, and it was correlated with the attention factors of SANS: the more severe the negative symptoms, the worse the neurocognitive function. However, NDS patients performed between DS and healthy controls in all cognitive domains, negative symptoms were not associated with cognitive function in the NDS group, which is consistent with previous reports of more severe cognitive impairment in DS patients $[7,36,58]$. There were significant differences in the neurocognitive impairment patterns between the two groups, mainly because of the differences in attention and executive function between the two groups. The persistent attention deficit may be the core cognitive impairment module in DS patients [29].

The severity of negative symptoms stabilized over time in patients with DS and NDS, while the severity of symptoms increased in patients with NDS. Thus, the widespread cognitive impairment in patients with DS is consistent with the earlier view that the deficiency syndrome is biologically unique and has more features of impairment than in patients with NDS [64]. A 2017 meta-analysis showed that cognitive deficits were more severe in DS patients, and language fluency was identified as one of the more severely affected cognitive areas, as alogia was a typical feature of the disease in schizophrenia patients with persistent negative symptoms [65]. Other studies have reported impaired sustained attention $[7,36,58-61]$ and visuospatial memory $[42,66]$ in DS patients. Patients with DS have been previously reported to have abnormal frontal and parietal lobe function. In recent years, a number of studies have shown that compared with female patients with schizophrenia, total brain volume, ventricule-brain ratio, frontal and temporal lobe decreases are more significant in male patients with schizophrenia. Meanwhile, sexual dimorphism has been found in geometric abnormalities of the white matter corpus callosum in patients with schizophrenia [67, 68]. Wheeler et al. found neuroimaging abnormalities in fronto-parietal function in DS patients [69]. Rowland and Voineskos, using motion diffusion tensor imaging studies, have identified reproducible impairment of white matter tracts in frontoparietal and frontotemporal circuits important for emotional processing emotional expression and social-emotional function [70, 71], all of 
which are characteristic of impaired patients with defective schizophrenia. Recent imaging studies have consistently found that patients with DS have reduced gray [72-75] and white matter volumes [74] in the temporal lobe region compared with patients with NDS. These findings regarding the structural abnormalities in specific brain regions in patients with different schizophrenia subtypes may explain the differences in core cognitive impairment modules between the DS and NDS groups.

Furthermore, the present study found the specific correlations of eye movement and clinical features with cognition in the DS group, which may represent a possible compensatory response to the functional deficit in DS patients. The present study found that the attention factors in the SANS in the DS group were significantly negatively correlated with the total MDRS score, attention factors, and structural factors, whereas the negative symptoms in the NDS group were not correlated with cognition. that TESL and RSS in patients with reported that TESL and RSS in patients with schizophrenia are negatively correlated with negative symptoms such as emotional withdrawal and flatness $[10,14,27,28,53,54]$. However, there was no significant correlation between positive symptoms and TESL and RSS. In the present study, NEF was significantly negatively correlated with the bizarre behavior factor of SAPS. Further, TESL was found to be negatively correlated with affective flattening factor of SANS in the DS group, but not in the NDS group. TESL was also positively associated with the total MDRS score, attention factor, and memory factor. In NDS patients, MESL was correlated with attention deficit of SANS, executive function and visuospatial ability of cognitive function, while negative symptoms were not correlated with cognition. This indicates that the shortening of total fixation distance in DS patients is related to the severity of negative symptoms and cognitive decline. The more severe the negative symptoms, the shorter the total fixation distance and the worse the cognitive function.

Recent studies have shown that negative symptoms play a key role in mediating the neurocognitive and social cognitive functions in patients with schizophrenia and in the prognosis of their functional outcomes [76]. Visual cognitive dysfunction in patients with schizophrenia was closely associated with the decline in social function, social status, independent living, working ability, and interpersonal communication ability [77-80], which may be the restrictions that hinder the social and vocational rehabilitation of patients [81]. DS is a subtype of schizophrenia. The characteristic negative symptoms of this subgroup include restriction of emotion, reduced range of emotion, poor speech, inhibition of interest, poor sense of purpose, and reduced social motivation $[43,57]$.
Further, patients with DS show more persistent, prominent negative symptoms and are associated with neurocognitive and social cognitive impairments [9]. Tsunoda et al. reported that a number of eye movement parameters were negatively associated with negative symptoms, particularly lack of willpower and blandness or dullness of emotion [82]. These findings suggested that exploratory eye movements are biomarkers for negative symptoms such as emotional withdrawal, emotional dullness, and mannerisms [27]. This clinical correlation suggested that negative effects on eye movement reflect underlying brain dysfunction that leads to communication disorders in relation to the environment and interpersonal relationships $[10,12]$. In addition, this study showed that MESL was positively correlated with total MDRS score, onset/retention factor, and concept formation factor in the NDS group. No correlation of TESL and negative symptoms with cognition was found in NDS patients, suggesting significant differences in eye movement characteristics between the two subgroups, which may result from the biological characteristics distinguishing DS from NDS.

To date, eye-tracking dysfunction remains a characteristic disorder limited to the risk of schizophrenia, although other factors have been reported to be abnormal in patients with schizophrenia [83, 84]. This relatively economical, safe and far-reaching eye-movement technique can well reflect the cognitive deficits of psychiatric patients. Therefore, the correlation between visual cognitive pattern and brain region structure in patients with mental disorders, especially schizophrenia, needs further study. At present, some studies have reported the relationship between eye movement characteristics and brain morphology and structure in patients with schizophrenia, providing valuable reference for cognitive function and social dysfunction in patients with schizophrenia [85-88], and also providing objective theoretical basis for clinical diagnosis and treatment [87-89]. Our preliminary findings suggest that cognitive and eye movement features may be important index in identifying the special type of schizophrenia patients with defective syndrome, and clinicians should pay more attention to cognitive evaluation and eye movement features in those patients. Considering the refractory nature of negative symptoms, more exploration should be implemented based on this subtype patients.

In the present study, we did find that both DS and NDS patients showed different eye movement features compared to healthy controls, the preliminary findings support that eye movement features may be a valuable bio-marks in the diagnosis of schizophrenia. TESL may be a characteristic eye movement symptom in DS patients, which is associated with serious negative 
symptoms and cognitive impairment in this schizophrenia subtype. However, as a cross-section study, we could not explore is role in predicting the prognosis in those patients. Hence, future studies are warranted to verify our findings and to explore its effects in predicting the prognosis in patients with schizophrenia, and future studies used more commonly used cognitive evaluation tools are also warranted to verify our findings.

\section{Limitations of the study}

Our study has several limitations. First, all patients were receiving antipsychotics, and although the type and dosage of antipsychotics were consistent between the two groups of patients, their influence on the study results cannot be ruled out. Second, patients in the two subgroups had different disease courses and age. Although the duration of disease and age had been controlled as a covariable in the statistical analysis of this study, it cannot be ruled out that it may have a certain influence on cognition. Third, the cognitive assessment tool we used was the Mattis Dementia Rating Scale (MDRS), so our results may not be generalizable to studies based on other tools, more studies with different tools are needed in the future to validate our findings. Fourth, we did not assess and control for the effects of IQ on cognitive function. In addition, only male patients were included in the present study, which may preclude our conclusion to female patients with schizophrenia, and further study need to explore the gender difference in eye movement features in DS and NDS patients. The future studies ought to also consider outpatients, female patients, and larger sample sizes (Additional file 1).

\section{Conclusions}

In summary, our findings provide empirical evidence for association between eye movement and cognitive function in patients with DS and NDS. TESL is significantly associated with negative symptoms and impaired cognitive function. Specifically, abnormalities between the two patient groups emphasize that visuoemotional and social functions were characteristically impaired in DS Patients. Patients with DS have persistent negative symptoms that lead to visual cognitive deficits in novel and complex problem-solving environments, and these deficits are partly related to cognitive indicators of persistent attention and executive dysfunction. These deficits begin to show with a reduced ability to scan complex visual environments effectively and eventually lead to environmental and social impairments. The present study suggests that deficit syndrome may be a specific subtype of schizophrenia.

\section{Abbreviations}

ANCOVA: Analysis of covariance; CPZ: Chlorpromazine; DS: Deficit schizophrenia; DSM-IV: Diagnostic and statistical manual-IV; EEM: Exploratory eye movement; GDB: Global Burden of Disease; MDRS-2: Mattis Dementia Rating Scale; MESL: Mean of eye scanning length; NDS: Non-deficit schizophrenia; NEF: Number of eye fixation; RSS: Responsive of search scores; SANS: Scale for the assessment of negative symptoms; SAPS: Scale for the assessment of positive symptoms; SCID: Structured clinical interview for DSM-IV; SDS: Schedule for the Deficit Syndrome; SPSS: Statistical package for social sciences; TESL: Total of eye scanning length.

\section{Supplementary Information}

The online version contains supplementary material available at https://doi. org/10.1186/s12868-021-00673-w.

Additional file 1: Table S1. Comparison of eye movement and cognitive function and eye movement parameters among for DS, NDS and HC groups stratified by marital status. Table S2. Comparison of eye movement and cognitive function and eye movement parameters among for DS, NDS and HC groups stratified by family history.

\section{Acknowledgements}

This study was supported by the National Key Research and Development Program of China (No. 2018YFC1314300), the National Natural Science Foundation of China (81971255), Social Development Foundation of Jiangsu Province, China (No. BE2019610), Jiangsu Provincial Medical Talent project (ZDRCA2016075) and Basic Research Project of Frontier Technology in Jiangsu Province, China (BK20192004D), Science and Technology Benefiting people Project of Jiangning District, Nanjing, Jiangsu Province, China (20212021 NJNQKJHMJHXM0). The authors thank the research volunteers for their participation.

\section{Authors' contributions}

XRZ was responsible for the analysis and interpretation of the study. LZ drafted the initial manuscript and was responsible for creation and design. XYF and CZ were all principle investigators and were responsible for creation and design of the study. LW, XMP, JC and FQZ were all involved in study design and interpretation of results. All authors reviewed the manuscript. All authors contributed to the manuscript. All authors read and approved the final manuscript.

\section{Funding}

This study was supported by the National Key Research and Development Program of China (No. 2018YFC1314300), the National Natural Science Foundation of China (81971255), Social Development Foundation of Jiangsu Province, China (No. BE2019610), Jiangsu Provincial Medical Talent project (ZDRCA2016075) and Basic Research Project of Frontier Technology in Jiangsu Province, China (BK20192004D), Science and Technology Benefiting people Project of Jiangning District, Nanjing, Jiangsu Province, China (20212021NJNQKJHMJHXMO).

\section{Availability of data and materials}

Data available on request from the corresponding author.

\section{Declarations}

\section{Ethics approval and consent to participate}

The Ethics Review Committee of the Second People's Hospital of Jiangning District, Nanjing approved the study (NO. 201910). All procedures performed in studies involving human participants were in accordance with the ethical standards of the institutional and/or national research committee and with the 1964 Helsinki declaration and its later amendments or comparable ethical standards. Informed written consent was obtained from all participants prior to the commencement of the study.

Consent for publication

Not applicable. 


\section{Competing interests}

The authors declare that they have no competing interests.

\section{Author details}

${ }^{1}$ Department of Geriatric Psychiatry, The Affiliated Nanjing Brain Hospital of Nanjing Medical University, No. 264 Guangzhou Road, Nanjing 210029, Jiangsu, China. ${ }^{2}$ Department of Psychiatry, The Second People's Hospital of Jiangning District, No. 50 ChenLing Road, Nanjing 210003, Jiangsu, China. ${ }^{3}$ Institute of Neuropsychiatry, The Affiliated Brain Hospital of Nanjing Medical University, No. 264 Guangzhou Road, Nanjing 210029, Jiangsu, China.

Received: 6 August 2021 Accepted: 9 November 2021

Published online: 24 November 2021

\section{References}

1. Barbato A. Schizophrenia and Public Health. Geneva, World Health Organization, Division of Mental Health and Prevention of Substance Abuse, 1998. http://www.who.int/mentalhealth/media/en/55.pdf.

2. Thaker GK, Carpenter WT. JR. Advances in schizophrenia. Nat Med. 2001;7:667-71. https://doi.org/10.1038/89040.

3. Vos T, Abajobir AA, Abate KH, et al. Global, regional, and national incidence, prevalence, and years lived with disability for 328 diseases and injuries for 195 countries, 1990-2016: a systematic analysis for the Global Burden of Disease Study 2016. Lancet. 2017;390:1211-59. https://doi.org/ 10.1016/S0140-6736(17)32154-2.

4. Charlson FJ, Ferrari AJ, Santomauro DF, Diminic S, Stockings E, Scott JG, McGrath JJ, Whiteford HA. Global epidemiology and burden of schizophrenia: findings from the global burden of disease study 2016. Schizophr Bull. 2018:44(6):1195-203. https://doi.org/10.1093/schbul/sby058.

5. Tandon R, Nasrallah HA, Keshavan MS. Schizophrenia, "just the facts" 5. Treatment and prevention. Past, present, and future. Schizophr Res. 2010;122(1-3):1-23. https://doi.org/10.1016/j.schres.2010.05.025.

6. Carpenter WTJR, Heinrichs DW, Wagman AM. Deficit and nondeficit forms ofschizophrenia: the concept. Am J Psychiatry. 1988;145(5):578-83. https://doi.org/10.1176/ajp.145.5.578.

7. Cohen AS, Docherty NM. Deficit versus negative syndrome in schizophrenia: prediction of attentional impairment. Schizophr Bull. 2004;30(4):82735. https://doi.org/10.1093/oxfordjournals.schbul.a007135.

8. Kirkpatrick B, Buchanan RW, Ross DE, Carpenter WJ. A separate disease within the syndrome of schizophrenia. Arch Gen Psychiatry. 2001;58(2):165-71. https://doi.org/10.1001/archpsyc.58.2.165.

9. Amador XF, Kirkpatrick B, Buchanan RW, et al. Stability of the diagnosis of deficit syndrome in schizophrenia. Am J Psychiatry. 1999;156:637-9. https://doi.org/10.1176/ajp.156.4.637.

10. Moriya H, Ando K, Kojima T, Shimazono Y, Ogiwara R. Eye movements during perception of pictures in chronic schizophrenia. Folia Psychiatr Neurol Jpn. 1972;26:189-99. https://doi.org/10.1111/j.1440-1819.1972. tb01124.x.

11. Holzman PS, Proctor LR, Hughes DW. Eye-tracking patterns in schizophrenia. Science. 1973;181:179-81. https://doi.org/10.1126/science.181.4095. 179.

12. Kojima T, Matsushima E, Ando K, et al. Exploratory eye movements and neuropsychological tests in schizophrenic patients. Schizophr Bull. 1992;18:85-94. https://doi.org/10.1093/schbul/18.1.85.

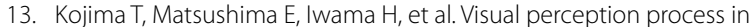
amphetamine psychosis and schizophrenia. Psychopharmacol Bull. 1986;22:768-73.

14. Kojima T, Matsushima E, Nakajima K, et al. Eye movements in acute, chronic, and remitted schizophrenics. Biol Psychiatry. 1990;27:975-89. https://doi.org/10.1016/0006-3223(90)90035-z.

15. Kojima T, Matsushima E, Ohta K, et al. Stability of exploratory eye movements as a marker of schizophrenia: a WHO multi-center study. Schizophr Res. 2001;52:203-13. https://doi.org/10.1016/s0920-9964(00)00181-X.

16. Kojima T, Potkin SG, Kharazmi M, Matsushima E, Herrera J, Shimazono Y. Limited eye movement patterns in chronic schizophrenic patients. Psychiatry Res. 1989;28:307. https://doi.org/10.1016/0165-1781(89)90211-4.

17. Matsukawa Y, Takahashi S, Aoki M, et al. Patients with systemic lupus erythematosus show a normal responsive search score in exploratory eye movement analysis: comparison with schizophrenia. Ann Rheum Dis. 2002;61:748-50. https://doi.org/10.1136/ard.61.8.748.

18. Matsushima E, Kojima T, Ohbayashi S, Ando H, Ando K, Shimazono Y. Exploratory eye movements in schizophrenic patients and patients with frontal lobe lesions. Eur Arch Psychiatry Clin Neurosci. 1992;241:210-4. https://doi.org/10.1007/BF02190255.

19. Obayashi S, Matsushima E, Okubo Y, Ohkura T, Kojima T, Kakuma T. Relationship between exploratory eye movements and clinical course in schizophrenic patients. Eur Arch Psychiatry Clin Neurosci. 2001;251:211-6. https://doi.org/10.1007/s004060170029.

20. Tonoya Y, Matsui M, Kurachi M, Kurokawa K, Sumiyoshi T. Exploratory eye movements in schizophrenia: Effects of figure size and the instruction on visual search. Eur Arch Psychiatry Clin Neurosci. 2002;252:255-61. https:// doi.org/10.1007/s00406-002-0390-5.

21. Suzuki M, Takahashi S, Matushima E, et al. Exploratory eye movement dysfunction as a discriminator for schizophrenia: a large sample study using a newly developed digital computerized system. Eur Arch Psychiatry Clin Neurosci. 2008;22:33-46. https://doi.org/10.1007/s00406-008-0850-7.

22. Miyahira A, Morita K, Yamaguchi H, Morita Y, Maeda H. Gender differences and reproducibility in exploratory eye movements of normal subjects. Psychiatry Clin Neurosci. 2000;103:31-6. https://doi.org/10.1046/j.14401819.2000.00632.x

23. Matsushima E, Kojima T, Ohta K, et al. Exploratory eye movement dysfunction in patients with schizophrenia: possibility as discriminator for schizophrenia. Psychiatry Res. 1988;5:289-95. https://doi.org/10.1016/ S0022-3956(98)00019-3.

24. Ryals AJ, Wang JX, Polnaszek KL, et al. Hippocampal contribution to implicit configuration memory expressed via eye movements during scene exploration. Hippocampus. 2015;25(9):1028-41. https://doi.org/10. 1002/hipo.22425.

25. Carvalho N, Laurent E, Noiret N, et al. Eye movement in unipolar and bipolar depression: a systematic review of the literature. Front Psychol. 2015;6(12):1809-1809. https://doi.org/10.3389/fpsyg.2015.01809.

26. Morita K, Miura K, Fujimoto M, et al. Eye movement as a biomarker of schizophrenia: using an integrated eye movement score. Psychiatry Clin Neurosci. 2017. https://doi.org/10.1111/pcn.12460.

27. Ryu H, Morita K, Shoji Y, Waseda Y, Maeda H. Abnormal exploratory eye movements in schizophrenic patients vs healthy subjects. Acta Neurol Scand. 2001;104:369-76. https://doi.org/10.1034/j.1600-0404.2001. 00279.x.

28. Nakayama H, Morita K, Mori K, Hirai S, Maeda H. Improvement of exploratory eye movements in schizophrenic patients during recovery period. Psychiatry Clin Neurosci. 2003;57:169-76. https://doi.org/10.1046/j.14401819.2003.01097.x.

29. Yu M, Tang XW, Wang X, et al. Neurocognitive impairments in deficit and non-deficit schizophrenia and their relationships with symptom dimensions and other clinical variables. PLoS ONE. 2015:10(9):e0138357.

30. Bryson G, Whelahan HA, Bell M. Memory and executive function impairments in deficit syndrome schizophrenia. Psychiatry Res. 2001;102(1):29_ 37. https://doi.org/10.1016/s0165-1781(01)00245-1.

31. Polgar P, Rethelyi JM, Balint $S$, Komlosi S, Czobor P, Bitter I. Executive function in deficit schizophrenia: what do the dimensions of the Wisconsin card sorting test tell us? Schizophr Res. 2010;122(1-3):85-93. https://doi. org/10.1016/j.schres.2010.06.007.

32. Cascella NG, Testa SM, Meyer SM, Rao VA, Diaz-Asper CM, Pearlson GD, Schretlen DJ. Neuropsychological impairment in deficit vs. non-deficit schizophrenia. Psychiatry Res. 2008;42(11):930-7. https://doi.org/10. 1016/j.jpsychires.2007.10.002.

33. Pegoraro LF, Dantas CR, Banzato CE, Fuentes D. Correlation between insight dimensions andcognitive functions in patients with deficit and nondeficit schizophrenia. Schizophr Res. 2013;147:91-4. https://doi.org/ 10.1016/j.schres.2013.02.041.

34. Polgar P, Farkas M, Nagy $O$, et al. How to find the way out from four rooms? The learning of" chaining" associations may shed light on the neuropsychology of the deficit syndrome of schizophrenia. Schizophr Res. 2008;99(1-3):200-7. https://doi.org/10.1016/j.schres.2007.06.027.

35. Farkas M, Polgar P, Kelemen O, Rethelyi J, Bitter I, Myers CE, Gluck MA, Keri S. Associative learning in deficit and nondeficit schizophrenia. Neuroreport. 2008;19(1):55-8. https://doi.org/10.1097/WNR.0b013e3282f2dff6. 
36. Rethelyi JM, Czobor P, Polgar P, et al. General and domain-specific neurocognitive impairments in deficit and non-deficit schizophrenia. Eur Arch Psychiatry Clin Neurosci. 2012;262(2):107-15. https://doi.org/10.1007/ s00406-011-0224-4.

37. Tyburski E, Pełka-Wysiecka J, Mak M, Samochowiec A, Bieńkowski P, Samochowiec J. Neuropsychological profile of specific executive dysfunctions in patients with the deficit and non-deficit schizophrenia. Front Psychol. 2017;8:e1459. https://doi.org/10.3389/fpsyg.2017.01459.

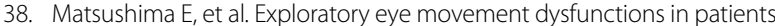
with schizophrenia: possibility as a discriminator for schizophrenia. J Psychiatr Res. 1998;32:289-95. https://doi.org/10.1016/S0022-3956(98)00019-3.

39. Akiyama T, Kojima T, Tsuchiya M. Studies on exploratory eye movement. Asian J Psychiatr. 2009;2:40-2. https://doi.org/10.1016/j.ajp.2009.01.008.

40. Coblentz JM, Mattis S, Zingesser L, Kasoffs S, Wisniewski HM, Katzman R. Presentile dementia clinical aspects and evaluation of cerebrospinal fluid dynamics. Arch Neurol. 1973;29:299-308. https://doi.org/10.1001/archn eur.1973.00490290039003.

41. First MB, Gibbons M, Spitzer RL, Williams JBW. Users Guide for the Structured Clinical Interview for DSM-IV Axis I Disorders Research Version (SCID-I, Version 2.0, February 1996 Final Version). New York: Biometrics Research Department; 1996.

42. Wang X, Yao S, Kirkpatrick B, Shi C, Yi J. Psychopathology and neuropsychological impairments in deficit and nondeficit schizophrenia of Chinese origin. Psychiatry Res. 2008;158:195-205. https://doi.org/10.1016/j. psychres.2006.09.007

43. Kirkpatrick B, Buchanan RW, McKenney PD, Alphs LD, Carpenter WT Jr. The schedule for the deficit syndrome: an instrument for research in schizophrenia. Psychiatry Res. 1989;30(2):119-23. https://doi.org/10.1016/ 0165-1781(89)90153-4.

44. Blanchard JJ, Cohen AS. The structure of negative symptoms within schizophrenia: implications for assessment. Schizophr Bull. 2006:32:23845. https://doi.org/10.1093/schbul/sbj013.

45. Fang $X$, Chen $L$, Wang D, Yu L, et al. Metabolic profiling identifies TC and LDL as potential serum biomarkers for depressive symptoms in schizophrenia. Psychiatry Res. 2019;11:281. https://doi.org/10.1016/j.psychres. 2019.112522.

46. Shakow D. Segmental set: a theory of the formal psychological defificit in schizophrenia. Arch Gen Psychiatry. 1962;6:1-17. https://doi.org/10.1001/ archpsyc.1962.01710190003001.

47. Williams LM, Loughland CM, Gordon E, et al. Visual scanpaths in schizophrenia: is there a deficit in face recognition? Schizophr Res. 1999;40:18999. https://doi.org/10.1016/s0920-9964(99)00056-0.

48. Loughland CM, Williams LM, Gordon E. Schizophrenia and affective disorder show different visual scanning behavior for faces: a trait versus state-based distinction? Biol Psychiatry. 2002. https://doi.org/10.1016/ s0006-3223(02)01356-2

49. Loughland CM, Williams LM, Harris AW. Visual scanpath dysfunction in first-degree relatives of schizophrenia probands: evidence for a vulnerability marker? Schizophr Res. 2004;67:11-21. https://doi.org/10.1016/ s0920-9964(03)00094-x.

50. Ohi K, Hashimoto R, Ikeda M, Yamamori H, et al. Glutamate networks implicate cognitive impairments in schizophrenia: genome-wide association studies of 52 cognitive phenotypes. Schizophr Bull. 2015;41:909-18. https://doi.org/10.1093/schbul/sbu171.

51. Boerman R, Cohen D, Schulte PF, et al. Prevalence of Vitamin D deficiency in adult outpatients with bipolar disorder or schizophrenia. J Clin Psychopharmacol. 2016;36(6):588-92. https://doi.org/10.1097/JCP.00000 00000000580

52. Levy DL, Holzman PS, Matthysse S, Mendell NR. Eye tracking and schizophrenia: a selective review. Schizophr Bull. 1994;20:47-62. https://doi.org/ 10.1093/schbul/20.1.47

53. Hori Y, Fukuzako H, Sugimoto $Y$, Takigawa M. Eye movements during the Rorschach test in schizophrenia. Psychiatry Clin Neurosci. 2002;56:409-18. https://doi.org/10.1046/j.1440-1819.2002.01030.x.

54. Minassian A, Granholm E, Verney S, Perry W. Visual scanning deficits in schizophrenia and their relationship to executive functioning impairment. Schizophr Res. 2004;74:69-79. https://doi.org/10.1016/j.schres. 2004.07.008.

55. Kraus MS, Keefe RE. Cognition as an outcome measure in schizophrenia. Br J Psychiatry Suppl. 2007;191(Suppl 50):s46-51. https://doi.org/10.1192/ bjp.191.50.s46.
56. Galderisi S, Maj M. Deficit schizophrenia: an overview of clinical, biological and treatment aspects. Eur Psychiatry. 2009;24(8):493-500. https://doi. org/10.1016/j.eurpsy.2009.03.001.

57. Kirkpatrick B, Galderisi S. Deficit schizophrenia: an update. World Psychiatry. 2008;7(3):143-7. https://doi.org/10.1002/j.2051-5545.2008.tb00181.x.

58. Cohen AS, Saperstein AM, Gold JM, Kirkpatrick B, Carpenter WT Jr, Buchanan RW. Neuropsychology of the deficit syndrome: new data and meta-analysis of findings to date. Schizophr Bull. 2007;33(5):1201-12. https://doi.org/10.1093/schbul/sbl066.

59. O'Leary DS, Flaum M, Kesler ML, Flashman LA, Arndt S, Andreasen NC. Cognitive correlates of the negative, disorganized, and psychotic symptom dimensions of schizophrenia. J Neuropsychiatry Clin Neurosci. 2000;12(1):4-15. https://doi.org/10.1176/jnp.12.1.4.

60. Bora E, Yucel M, Pantelis C. Cognitive functioning in schizophrenia, schizoaffective disorder and affective psychoses: meta-analytic study. Br J Psychiatry. 2009;195(6):475-82. https://doi.org/10.1192/bjp.bp.108. 055731.

61. Chen $C_{\text {, Jiang } W}$, Zhong $N$, et al. Impaired processing speed and attention in firstepisode drug naive schizophrenia with deficit syndrome. Schizophr Res. 2014;159(2-3):478-84. https://doi.org/10.1016/j.schres.2014.09.005.

62. Steven Mattis. Dementia Rating Scale Professional Manual. 1988.

63. Chan AS, Choi MK, Salmon DP. The effects of age, education, and gender on the Mattis Dementia Rating Scale performance of elderly Chinese and American individuals. J Gerontol B Psychol Sci Soc Sci. 2001;56(6):356-63. https://doi.org/10.1093/geronb/56.6.p356.

64. Chemerinski E, Reichenberg A, Kirkpatrick B, et al. Three dimensions of clinical symptoms in elderly patients with schizophrenia: prediction of six-year cognitive and functional status. Schizophr Res. 2006;85:12-9. https://doi.org/10.1016/j.schres.2006.03.002.

65. Bora E, BinnurAkdede B, Alptekin K. Neurocognitive impairment in deficit and non-deficit schizophrenia: a meta-analysis. Psychol Med. 2017. https://doi.org/10.1017/S0033291717000952.

66. Szendi I, Racsmany M, Cimmer C, et al. Two subgroups of schizophrenia identified by systematic cognitive neuropsychiatric mapping. Eur Arch Psychiatry Clin Neurosci. 2010;260(3):257-66. https://doi.org/10.1007/ s00406-009-0073-6.

67. Savadjiev P, Seidman LJ, Thermenos H, et al. Sexual dimorphic abnormalities in white matter geometry common to schizophrenia and nonpsychotic high-risk subjects: evidence for a neurodevelopmental risk marker? Human Brain Mapp. 2016;37(1):254-61. https://doi.org/10.1002/ hbm.23026

68. Savadjiev $P$, Whitford TJ, Hough ME, et al. Sexually dimorphic white matter geometry abnormalities in adolescent onset schizophrenia. Cereb Cortex. 2014;24(5):1389-96. https://doi.org/10.1093/cercor/bhs422.

69. Wheeler AL, Wessa M, Szeszko PR, et al. Further neuroimaging evidence for the deficit subtype of schizophrenia: a cortical connectomics analysis. JAMA Psychiatry. 2015;72(5):446-55. https://doi.org/10.1001/jamapsychi atry.2014.3020.

70. Voineskos AN, Foussias G, Lerch J, et al. Neuroimaging evidence for the deficit subtype of schizophrenia. JAMA Psychiatry. 2013;70(5):472-80. https://doi.org/10.1001/jamapsychiatry.2013.786.

71. Rowland LM, Spieker EA, Francis A, Barker PB, Carpenter WT, Buchanan RW. White matter alterations in deficit schizophrenia. Neuropsychopharmacology. 2009;34(6):1514-22. https://doi.org/10.1038/npp.2008.207.

72. Galderisi S, Quarantelli M, Volpe U, et al. Patterns of structural MRI abnormalities in deficit and nondeficit schizophrenia. Schizophr Bull. 2008;34(2):393-401. https://doi.org/10.1093/schbul/sbm097.

73. Cascella NG, Fieldstone SC, Rao VA, Pearlson GD, Sawa A, Schretlen DJ. Gray-matter abnormalities in deficit schizophrenia. Schizophr Res. 2010;120(1-3):63-70. https://doi.org/10.1016/j.schres.2010.03.039.

74. Chen WJ. Taiwan Schizophrenia Linkage Study: lessons learned from endophenotype-based genome-wide linkage scans and perspective. Am J Med Genet B Neuropsychiatr Genet. 2013;162B(7):636-47. https://doi. org/10.1002/ajmg.b.32166.

75. Fischer BA, Keller WR, Arango C, et al. Cortical structural abnormalities in deficit versus nondeficit schizophrenia. Schizophr Res. 2012;136(1-3):514. https://doi.org/10.1016/j.schres.2012.01.030.

76. Lin $\mathrm{CH}$, Huang $\mathrm{CL}$, Chang YC, et al. Clinical symptoms, mainly negative symptoms, mediate the influence of neurocognition and social cognition on functional outcome of schizophrenia. Schizophr Res. 2013;146(13):231-7. https://doi.org/10.1016/j.schres.2013.02.009. 
77. Addington J, Saeedi H, Addington D. Facial affect recognition: a mediator between cognitive and social functioning in psychosis. Schizophr Res. 2006;85:142-50. https://doi.org/10.1016/j.schres.2006.03.028.

78. Couture SM, Penn DL, Roberts DL. The functional significance of social cognition in schizophrenia: a review. Schizophr Bull. 2006;32(Suppl 1):S44-63. https://doi.org/10.1093/schbul/sbl029.

79. Eack SM, Greeno CG, Pogue-Geile MF, Newhill CE, Hogarty GE, Keshavan MS. Assessing social-cognitive deficits in schizophrenia with the MayerSalovey-Caruso Emotional Intelligence Test. Schizophr Bull. 2010;36:37080. https://doi.org/10.1093/schbul/sbn091.

80. Kee KS, Horan WP, Salovey P, et al. Emotional intelligence in schizophrenia. Schizophr Res. 2009;107:61-8. https://doi.org/10.1016/j.schres.2008.08. 016.

81. Penn DL, Sanna LJ, Roberts DL. Social cognition in schizophrenia: an overview. Schizophr Bull. 2008;34:408-11. https://doi.org/10.1093/schbul/ sbn014.

82. Tsunoda M, Kurachi M, Yuasa S, et al. Scanning eye movements in schizophrenic patients: relationship to clinical symptoms and regional cerebral blood flflow using 123I-IMP SPECT. Schizophr Res. 1992;7:159-68. https:// doi.org/10.1016/0920-9964(92)90046-8.

83. Lencer R, Sprenger A, Reilly JL, et al. Pursuit eye movements as an intermediate phenotype across psychotic disorders: evidence from the B-SNIP study. Schizophr Res. 2015;169(1-3):326-33. https://doi.org/10.1016/j. schres.2015.09.032.

84. Elahipanah A, Christensen BK, Reingold EM. Attentional guidance during visual search among patients with schizophrenia. Schizophr Res. 2011;131(1-3):224-30. https://doi.org/10.1016/j.schres.2011.05.026.
85. Padmanabhan UL, Tandon N, Haller CS, et al. Correlations between brain structure and symptom dimensions of psychosis in schizophrenia, schizoaffective, and psychotic bipolar i disorders. Schizophr Bull. 2015;41(1):154-62. https://doi.org/10.1093/schbul/sbu075.

86. Qiu L, Yan H, Zhu R, et al. Correlations between exploratory eye movement, hallucination, and cortical gray matter volume in people with schizophrenia. BMC Psychiatry. 2018. https://doi.org/10.1186/ s12888-018-1806-8.

87. Yasuda Y, Okada N, Nemoto K, et al. Brain morphological and functional features in cognitive subgroups of schizophrenia. Psychiatry Clin Neurosci. 2020;74(3):191-203. https://doi.org/10.1111/pcn.12963.

88. Morita K, Miura K, Fujimoto M, et al. Eye-movement characteristics of schizophrenia and their association with cortical thickness. Psychiatry Clin Neurosci. 2019;73(8):508-9. https://doi.org/10.1111/pcn.12865.

89. Billeke P, Aboitiz F. Social cognition in schizophrenia: from social stimuli processing to social engagement. Front Psychiatry. 2013. https://doi.org/ 10.3389/fpsyt.2013.00004.

\section{Publisher's Note}

Springer Nature remains neutral with regard to jurisdictional claims in published maps and institutional affiliations.
Ready to submit your research? Choose BMC and benefit from:

- fast, convenient online submission

- thorough peer review by experienced researchers in your field

- rapid publication on acceptance

- support for research data, including large and complex data types

- gold Open Access which fosters wider collaboration and increased citations

- maximum visibility for your research: over 100M website views per year

At BMC, research is always in progress.

Learn more biomedcentral.com/submissions 